\title{
Stress echocardiography in horses - a review
}

\author{
Charlotte Sandersen and Hélène Amory \\ University of Liege, Faculty of Veterinary Medicine, Department of Clinical Sciences, Liege, Belgium
}

\begin{abstract}
Summary
The increasing number of publications in the field of equine stress echocardiography demonstrates the growing interest in this area. Stress echocardiography consists of B-and/or M-mode echocardiography under active or passive stimulation of the heart, where the pre-stimulation images are compared to those obtained during or immediately after stimulation. In human medicine, stress echocardiography is mainly used as a routine tool in diagnosis and prognosis of coronary artery disease, but also in the evaluation of hypertrophied and dilated cardiomyopathy and valvular diseases. In horses, the principal indications include the detection of exercised-induced myocardial insufficiency and refining the prognosis of low- and mid-grade valvular diseases. The two major cardiac stressors that can be used in horses are (1) physical exercise, which has the major disadvantage of a rapid decline in heart rate in the immediate post-exercise period and (2) pharmacological stimulation, which ideally consists of dobutamine infusion in combination of a parasympatholytic drug, in order to overcome the strong dobutamine-induced baroreceptor reflex in horses. Most stress echocardiographic studies performed in horses demonstrated a significant decrease of left ventricular length, diameter, area and volume in response to stimulation. Other studies also revealed a stimulation-induced increase in the interventricular septum, left ventricular free wall thickness, and left ventricular fractional shortening. Some of these changes seemed to be more pronounced during pharmacological stimulation than after exercise. One study described the application of a semi-quantitative wall motion scoring system in horses. Exercise as well as pharmacological stress echocardiography enhances the diagnostic possibilities in equine medicine, because it increases the chance to detect a problem that is not present at rest. Furthermore, this technique could help to investigate the relationship between valvular insufficiencies and ventricular dysfunction.
\end{abstract}

Keywords: exercise-induced myocardial dysfunction, poor performance, wall motion index, dobutamine, atropine

\section{Stressechokardiographie beim Pferd - eine Übersicht}

In den vergangenen Jahren hat das Interesse an Stressechokardiographie beim Pferd deutlich zugenommen, was durch die steigende Anzahl der Publikationen zu dem Thema belegt wird. Die Technik basiert auf der Anwendung von Schnittbildechokardiographie in Kombination mit aktiver oder passiver Stressinduktion, wobei die unter Stimulation gewonnenen Bilder mit denen im Ruhezustand verglichen werden. In der Humanmedizin wird Stressechokardiographie hauptsächlich als Routinemittel in der Diagnose und Prognose von Koronarerkrankungen, und darüber hinaus in der Bewertung von hypertrophischen und dilatierten Kardiomyopathien und Herzklappenerkrankung eingesetzt. Bei Pferden ist die Untersuchung des Herzens im stimulierten Zustand vor allem zur Erkennung von belastungsinduzierter Myokardinsuffizienz und zur genaueren Prognosestellung von gering- und mittelgradigen Klappeninsuffizienzen von Nutzen. Ähnlich wie in der Humanmedizin stehen grundsätzlich zwei Formen der Stressinduktion zur Verfügung. Aktive Belastung durch Longen- oder Laufbandbelastung, hat den Vorteil, dass sie leicht verfügbar und gut verträglich ist, hat allerdings den wesentlichen Nachteil, dass die Herzfrequenz rapide nach Ende der Belastung unter 100 Schläge/Minute absinkt und dass der Zeitraum der zur echokardiographischen Bildermittlung zur Verfügung steht, sehr kurz ist. Bei der pharmakologischen Stressinduktion hat sich eine Kombination aus einer Daverinfusion des beta-Agonisten Dobutamin und dem Parasympatholytikums Atropin bewehrt. Atropin hat die Aufgabe, den durch Dobutamin ausgelösten Barorezeptor-Reflex herabzusenken, und bewirkt damit eine Steigerung der Herzfrequenz. Diese Kombination hat sich gegenüber anderen Stressoren als vorteilhaft erwiesen, da sie gut verträglich ist, weniger kardiomyotoxisch ist und seltener Herzarrhythmien auslöst als z.B. alleiniges hochdosiertes Dobutamin oder Adrenalin. In den meisten Studien wurden bei den Pferden das linke Herz von rechts in B- und M-mode Technik dargestellt. In einigen Studien wurde dopplerechokardiographisch der Pulmonararterien- und Aortenfluss gemessen und daraus das Schlagvolumen berechnet. Dabei belegen alle Studien unter Stimulation eine Verminderung des Durchmessers, der Länge, des Volumens und des Querschnittsfläche des linken Ventrikels. Außerdem wurde in einigen Studien eine Zunahme der Wandstärke des Interventrikularseptums und der linksventrikulären Hinterwand festgestellt. Die linksventrikuläre Kürzungsfraktion nimmt in der Regel unter Stimulation zu. Diese Veränderungen können sowohl nach aktiver als auch nach passiver Stressinduktion beobachtet werden; sie sind teilweise ausgeprägter nach pharmakologischer Stimulation. Darüber hinaus wurde in einer Studie an gesunden und herzkranken Pferden der in der Humanmedizin übliche semiquantitative Ansatz vor und nach einer Laufbandbelastung getestet. Dabei wurde eine Längsansicht des linken Ventrikels in sechs Segmente unterteilt und diese vor und nach der Laufbandbelastung anhand ihres Bewegungsmusters mit den Graden 1 für Normokinesie, 2 für Hypokinesie, 3 für Akinesie und 4 für Dyskinesie beurteilt. Die Summe der Grade geteilt durch die Anzahl der Segmente ergab bei herzgesunden Pferden einen mittleren Wandbewegungsindex von 1.1 vor und 1.12 nach Belastung und bei herzkranken Pferden einen mittleren Wandbewegungsindex von 1.5 vor und 1.52 nach der Belastung. Diese viel versprechende Methode zeigt, dass auch ein semiquantitativer Ansatz bei Pferden sinnvoll ist. Stressechokardiographie stellt eine Bereicherung der Diagnostik in der Pferdemedizin dar, da sie die Untersuchung des Herzens während oder sofort nach der Belastung ermöglicht. Dadurch können Veränderungen erkannt werden, die im Ruhezustand nicht zu erkennen sind. Außerdem könnte diese Methode eventuell helfen, die pathophysiologischen Zusammenhänge zwischen Ventrikeldysfunktion und Klappenkrankheiten zu erklären.

Schlüsselwörter: belastungsinduzierte Myokardinsuffizienz, Leistungsintoleranz, Wandbewegungsindex, Dobutamin, Atropin

\section{Introduction}

There is a high incidence of cardiac murmurs in athletic horses (Glendenning 1972). A study including 545 racehorses reported cardiac murmurs in $68 \%$ of 545 racehorses (Patte- son and Cribbs 1993). Another study demonstrated cardiac murmurs in $81.1 \%$ of 846 Thoroughbreds (Kriz et al. 2000), but failed to demonstrate a correlation between presence of cardiac murmurs and race performance. Determining the sig- 
nificance of cardiac murmurs in horses with poor performance remains a difficult task (Mitten 1996) because, even if the majority of these murmurs are physiological, some of them are clinically significant.

The possibilities for objective evaluation of heart murmurs in horses have significantly increased with the introduction of echocardiography in equine medicine. Two-dimensional and M-mode echocardiography gives information on dimensions of the different cavities and walls of the heart, while Doppler echocardiography allows determination of the direction and of the velocity of the blood flow within the heart (Blissit and Bonagura 1995a, Blissit and Bonagura 1995b, Reef 1992). Regurgitant flow can be detected and a semi-quantitative measurement of the severity of the regurgitation can be made by measuring the spatial distribution of the regurgitant jet in the receiving chamber (jet area, length and width). However, quantifying the regurgitation does not always provide a prognosis. Furthermore, determination of the prognosis of cardiac murmurs has been shown to be a crucial point in pre-purchase examination as demonstrated in a study by Verdegaal et al. (2002). The authors of this study found that from 56 horses with heart murmurs detected at pre-purchase examination only 24 were sold for the expected price, while 12 were sold for a lower price and 20 were not sold at all. Therefore the question arises whether other techniques, like e.g. stress echocardiography, could provide additional information on the prognosis of valvular insufficiencies in horses.

Apart from the prognostic evaluation of valvular insufficiencies, stress echocardiography will be applicable in the diagnosis of exercise-induced myocardial dysfunction, which has been described as a cause of poor performance in horses. For instance, in a study including 348 cases with poor performance, exercised-induced myocardial dysfunction was claimed to be the aetiology in 5.5\% of the horses studied (Martin et al. 2002). A slightly higher incidence was found by Reef et al. (1997), who suspected exercise-induced myocardial dysfunction in $8 \%$ of 250 horses examined for poor performance. The majority of these horses had no other abnormality detected during resting or treadmill examination, and the diagnosis of exercise-induced myocardial dysfunction was made on the basis of stress echocardiography.

\section{Stress echocardiography in humans}

Indications

In human medicine, stress echocardiography was first described in 1977 as a combination of two-dimensional echocardiography with physical, pharmacological or electrical stress applied to the heart (Autenrieth et al.). In human patients, stress echocardiography is most frequently used in the diagnosis and prognosis of coronary artery disease (Cohen et al. 1991). However, the indications for stress echocardiography have also expanded into risk evaluation of patients undergoing vascular surgery (Poldermans et. al. 1993, Poldermans et al. 1995), evaluation of chest pain (Geleijnse et al. 2000), assessment of myocardial viability (Smart et al. 1993, Watada et al. 1994, Previtali et al. 1993, Pierard et al. 1990), detection of occult pulmonary hypertension (Armstrong and Zoghbi 2005), assessment of mitral valvular disease (Wu et al. 2004) and the evaluation of prosthetic mitral valve (Leavitt et al. 1991).

\section{Exercise stress echocardiography}

Both treadmill and bicycle exercise are used to perform exercise stress echocardiography. When a treadmill test is performed, scanning during exercise is not feasible, so most protocols rely on post-exercise imaging within one minute after cessation of exercise (Armstrong and Zoghbi 2005). This technique assumes that exercise-induced wall motion abnormalities persist during this period. However, due to rapid recovery of the wall motion abnormalities after exercise, false-negative results occur (Picano 2004). The advantages of treadmill exercise echocardiography are widespread availability of treadmill systems and the wealth of clinical experience with this form of stress testing. Bicycle exercise echocardiography is performed during either an upright or a recumbent posture. The patient pedals against an increasing workload while echocardiographic imaging is performed. The major advantage of bicycle exercise is the opportunity to obtain images during various levels of exercise rather than relying on post-exercise imaging. Exercise is the prototype of ischemic stress and the most commonly stressor used to perform stress echocardiography in humans (Picano 2004). However, it has been shown that $20 \%$ of the patients undergoing exercise stress echocardiography are unable to exercise, $20 \%$ exercise submaximally, and $20 \%$ have an uninterpretable ECG (Picano 2004). In addition, exercise induces hyperventilation and excessive chest wall movement, which degrades image quality, increases inter-observer variability, and therefore lowers diagnostic accuracy. These factors explain the popularity of pharmacological stress induction.

\section{Pharmacological stress echocardiography}

Although different pharmacological stressors are used in human stress echocardiography, dobutamine is by far the most commonly used (Marwick 2005). The standard dobutamine stress protocol consists of continuous intravenous infusion of dobutamine in 3 minutes increments, starting with 5 $\mu \mathrm{g} / \mathrm{kg} / \mathrm{min}$, and increasing to $10,20,30$ and $40 \mu \mathrm{g} / \mathrm{kg} / \mathrm{min}$. If no endpoint is reached, atropine in doses of $0.25 \mathrm{mg}$ up to a maximum of $1 \mathrm{mg}$ is added to the dobutamine infusion rate of $40 \mu \mathrm{g} / \mathrm{kg} / \mathrm{min}$.

\section{Data acquisition and interpretation}

Independently of the cardiac stressor applied during stress echocardiography, a standard 12-lead ECG and blood pressure are continuously monitored before and during the test. Echocardiographic monitoring is continuously employed and intermittently recorded before, during and after cessation of stress. According to the American Heart Association, the left ventricle is imaged in three longitudinal views: (1) a horizontal long-axis view, (2) a vertical four-chamber view, and (3) a two chamber view and in three short-axis views: (1) at the level of the mitral valve, (2) at the level of the papillary muscles and (3) at the level of the apex (Schiller et al. 1989, Cerqueira et al. 2002). The left ventricle is divided into $16 \mathrm{seg}$ - 
ments that are scored subjectively for their contractility, where $0=$ hyperkinetic, $1=$ normokinetic, 2 = hypokinetic, $3=$ akinetic, and $4=$ dyskinetic (Carstensen et al. 1995). The sum of the score divided by the number of segments gives the unit-less wall motion index. This semi-quantitative method is less time consuming than a quantitative approach, but subject to variation and intensive training is required before maximal diagnostic yield is reached (Picano et al. 1991).

Diagnostic endpoints of the stress test are: reaching the maximal dose (for pharmacological stress) or maximal workload (for exercise testing); achievement of target heart rate; obvious echocardiographic positivity (with akinesia of three or more left ventricular segments); severe chest pain; or obvious electrocardiographic positivity (with $>2 \mathrm{mV} \mathrm{ST} \mathrm{segment} \mathrm{shift).}$ Submaximal non-diagnostic endpoints of stress echo are intolerable symptoms or limiting asymptomatic effects such as hypertension, with systolic blood pressure higher than 220 $\mathrm{mmHg}$ or diastolic blood pressure higher than $120 \mathrm{mmHg}$; hypotension with more than $30 \mathrm{mmHg}$ drop in blood pressure; supraventricular arrhythmias, such as supraventricular tachycardia or atrial fibrillation; and complex ventricular arrhythmias.

\section{Stress echocardiography in horses}

\section{Exercise electrocardiography}

In the sixties, telemetric exercise electrocardiography was described in horses (Banister and Purvis 1968, Bassan and Ott 1968) and since then became a routine technique for the detection of exercise-related cardiac arrhythmias. Although equine ECGs give useful information about heart rate and rhythm, it provides little or no information about the relative or absolute sizes of the ventricles (Patteson 1995). Due to the widespread distribution of the Purkinje fibres, which extend throughout the equine myocardium, the depolarization spreads out in several directions at once. Therefore these forces tend to cancel each other out; leading to a silent depolarisation of a large portion of the ventricular mass on a surface ECG. This is in contrast to humans, where the surface ECG gives valuable information about heart size and myocardial depolarization activities. In human medicine, a depression or an elevation of the ST segments are indicators of coronary artery disease and myocardial infarction, respectively (Dagenais et al. 1982, Henry et al. 2006). There is no evidence that myocardial ischemia leads to similar changes in equine ECGs.

\section{Exercise stress echocardiography}

In 1977, echocardiography was described for the first time in horses by Pipers and Hamlin. Since then, echocardiography had become a routine technique in equine cardiology. However, examining the equine heart by ultrasound under stress conditions was described only recently.

In 1994, Reef et al. described for the first time the use of postexercise echocardiography in horses. The authors stated that horses suffering from exercise-induced myocardial dysfunction may have a normal echocardiographic examination at rest, or they might have only a low-grade dyskinesia or akinesia, of which its significance is unknown. The normal equine heart should respond to exercise by an increase in the systolic thickening of the inter-ventricular septum and of the left ventricular free wall and an increase in fractional shortening over the resting values. Myocardial dysfunction exists if fractional shortening is unchanged or decreased, no thickening of septum and free wall, or dyskinetic or akinetic movements are detected immediately after exercise.

Two studies, one by Marr et al. (1999) and one by Sampson et al. (1999) performed post-exercise echocardiography in healthy horses. Although the primary goal of these two studies was not to detect exercise-induced myocardial dysfunction, but rather to investigate the physiological response of the heart to exercise, they give invaluable information about postexercise echocardiography in healthy horses. Marr et al. (1999) measured the left ventricular M-mode parameters in five healthy horses before and after treadmill exercise in cold and hot/humid environment. Sampson et al. (1999) described the relationship between $\mathrm{VO}_{2 \max }$ and cardiac output to heart score and echocardiographic parameters in six healthy Thoroughbreds performing a maximal treadmill exercise test. Both studies clearly showed that after cessation of exercise, the left ventricular echocardiographic parameters quickly return to pre-exercise levels. A similar conclusion was made by Durando et al. (2002) who measured right ventricular pressure dynamics in nine healthy Thoroughbreds during and directly after a maximal treadmill exercise and correlated the findings to left ventricular fractional shortening and wall motion indices. In this study, right ventricular pressure determinants had returned to pre-exercise values within 60 to 120 seconds after the end of exercise. The rapid return to baseline of cardiac parameters in the immediate post-exercise period is also well known in human medicine where it is generally advised to perform the echocardiographic recording within one minute after the end of exercise in order to guarantee a reliable specificity of the test (Armstrong and Zoghbi 2005). In the three studies mentioned above (Marr et al 1999, Sampson et al. 1999, Durando et al. 2002), the horses underwent a standardised treadmill test. As a high speed treadmill is not commonly available, the question arose weather alternative forms of exercise can be used to perform stress echocardiography in horses. Gehlen et al. (2005a) compared the effects of treadmill versus lunging exercise on left ventricular $M$ mode parameters in 20 healthy horses. The horses attained a mean maximal heart rate of $155 \pm 12 \mathrm{bpm}$ during treadmill exercise and a mean maximal heart rate of $169 \pm 14$ during lunging exercise. Both forms of stress induction allowed obtaining echocardiographic recordings within two minutes after the end of exercise. The mean heart rate at the time of echocardiographic recording was $114 \pm 6$ bpm after treadmill exercise and $100 \mathrm{bpm}$ after lunging exercise. In both groups, a significant increase in left ventricular wall thickness and fractional shortening was observed and there was no significant difference between the results obtained after treadmill or after lunging exercise. Twelve of the twenty horses were also tested three to five minutes after cessation of treadmill exercise when the mean heart rate was $78 \pm 3$ bpm, but no significant difference to pre-exercise values was observed.

All of the studies mentioned above based their evaluation of the cardiac stress effect on the measurement of $M$ - and B- 
mode echocardiographic parameters. This method is time consuming and has not taken hold in human medicine, where interpretation is generally based on a semi-quantitative scoring system. The first attempt to introduce a semi-quantitative wall motion scoring system in equine stress echocardiography was made by Durando et al. (2002), who described this technique in healthy horses before and after a maximal treadmill exercise. This group used an imaging software system that displayed pre- and post-exercise images side-byside at simulated matched heart rates allowing critical assessment of segmental wall motion as illustrated in Figure 1. The

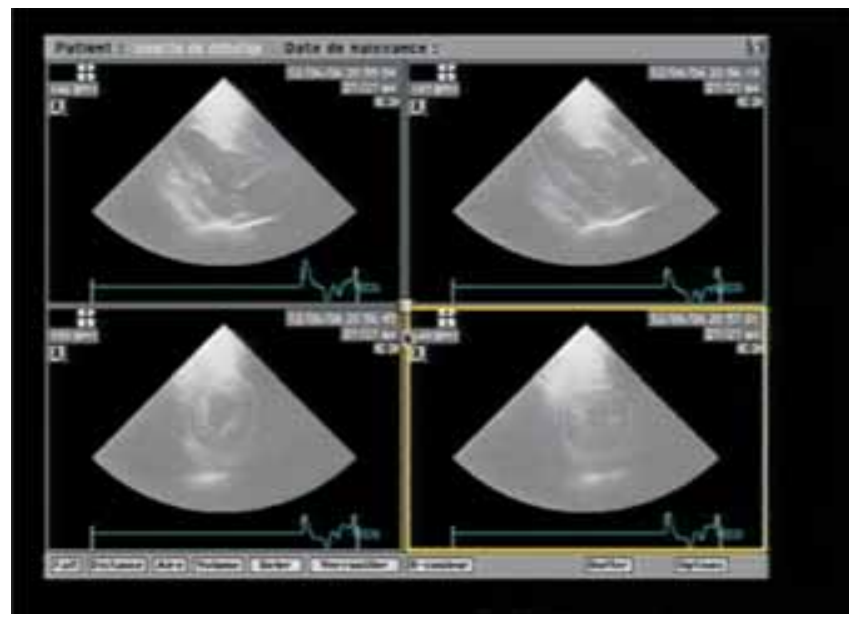

Fig 1 Echopac-processed images of the left ventricle in a right parasternal B-mode views at different heart rates. This program enables to display cardiac cycles of different length at the same speed in order to further increase the possibility to detect wall motion abnormalities.

Echopac-Bilder des linken Ventrikel in rechter parasternaler B-modeAnsicht bei unterschiedlichen Herzfrequenzen. Das Programm ermöglicht die Darstellung von Herzzyklen unterschiedlicher Längen bei der selben Geschwindigkeit, um die Erkennung abnormer Herzwandbewegungen zu verbessern.

mean wall motion index was 1.01 before and 1.12 after exercise.

A similar technique was then applied by Gehlen et al. (2005b) who studied 23 healthy horses and 12 horses suffering from different degrees of cardiac diseases (5 of them had low-grade cardiac disease, 5 had moderate-grade cardiac disease and 2 had severe cardiac disease). The left ventricle was visualised in B-mode before and directly after treadmill exercise. The left ventricle was divided into 6 segments of equal size (Figure 2). Each segment was evaluated before and after exercise following the criteria according to the criteria summarised in table 1 (Gehlen et al. 2005b). The majority of the healthy horses showed no abnormal contraction of the six segments before or after exercise. However, in nine healthy horses a hypokinesia of the papillary muscle segment was observed before exercise, and persisted after exercise in four of them. The kinetic score at rest was $1.10 \pm 0.20$ in healthy horses and $1.50 \pm 0.40$ in horses suffering from cardiac disease. The kinetic score after exercise was $1.12 \pm$ 0.16 in healthy horses and $1.52 \pm 0.40$ in those suffering from cardiac disease. Horses with mild cardiac disease had a wall motion index that was significantly different from that of healthy horses after exercise but not at rest. The two horses with severe cardiac disease did not undergo exercise; both had abnormal wall motion in five out of six segments at rest.

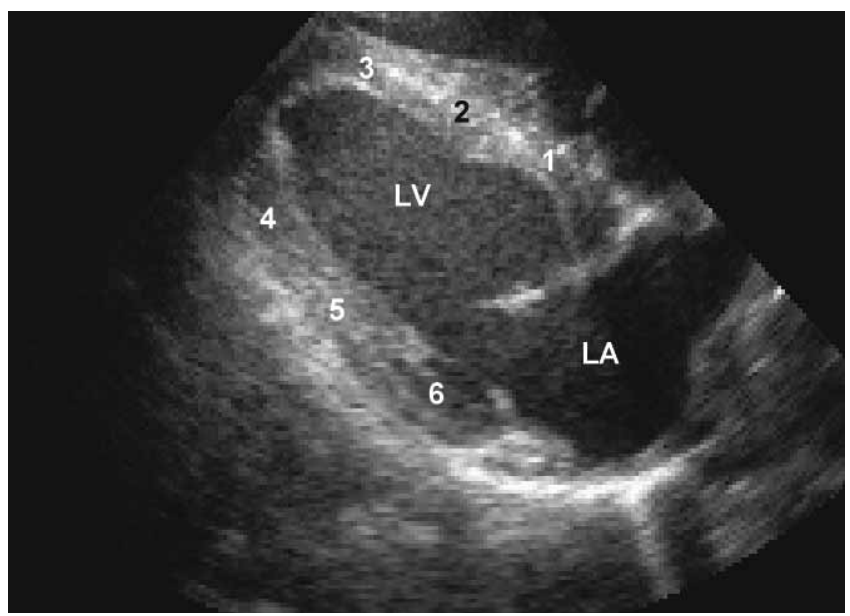

Fig 2 Right paraseternal B-mode view of the left ventricle. Six (1-6) segments for semi-quantitative evaluation of wall motion as described by Gehlen et al. (2005). LA = left atrium, LV = left ventricle Rechte parasternale B-mode-Ansicht des linken Ventrikels. Gehlen et al. (2005) beschreiben sechs (1-6) Segmente für die semiquantitative Untersuchung der Wandbewegung. $L A=$ linker Vorhof, $L V=$ linker Ventrikel.

These results suggest that wall motion analysis in post-exercise stress echocardiography could be particularly useful to evaluate low-grade cardiac disease in horses.

\section{Pharmacological stress echocardiography}

Numerous studies demonstrated the need for maximal or near-maximal exercise as well as echocardiographic recordings performed quickly after cessation of exercise in order to obtain reliable results (Reef et al.1994, Reef 1997, Marr et al. 1999, Sampson et al. 1999, Reef 2001, Durando et al. 2002). To obviate the problem of the rapid drop in heart rate in the post-exercise period, several pharmacological stress protocols have been developed in horses (Frye et al. 2003, Gehlen et al. 2004, Sandersen et al. 2005a, Gehlen et al. 2006, Sandersen et al. 2006). In 2003, Frye et al. compared the effect of a maximal treadmill exercise to a high-dose dobutamine challenge on left ventricular $\mathrm{M}$-mode parameters

Table 1 Wall motion scores applied in equine stress echocardiography according to Gehlen et al. (2005 c) Herzwandbewegungsscores angewnadt auf die Stressechokardiographie beim Pferd nach Gehlen et al. (2005c).

\begin{tabular}{lll}
\hline Kinetic score & \multicolumn{1}{c}{ Kinetics } & \multicolumn{1}{c}{ Description } \\
\hline 1 & normokinesia/ hyperkinesia & regular systolic wall thickening with inward movement of the wall \\
2 & hypokinesia & decreased systolic wall thickening and inward movement of the wall \\
3 & akinesia & nonexistent systolic wall thickening without inward movement of the wall \\
4 & dyskinesia & asymmetric systolic wall thickening and asymmetric inward movement of the wall \\
\hline
\end{tabular}


of healthy horses. The left ventricular M-mode parameters obtained after exercise were not significantly different from those measured after infusion of $50 \mu \mathrm{g} / \mathrm{kg} / \mathrm{min}$ of dobutamine. However, all of the 14 horses tested showed various degrees of restlessness, three of them showed premature ventricular complexes and three of them showed ventricular tachycardia during the dobutamine challenge. Furthermore, two out of ten horses examined post-mortem showed histopathological lesions highly indicative of catecholamine-induced myocardial toxicity.

In 2004, Gehlen et al. applied a low-dose dobutamine stress test $(5 \mu \mathrm{g} / \mathrm{kg} / \mathrm{min})$ to 16 horses with cardiac murmurs and to 27 horses without cardiac murmur. Cardiac auscultations as well as B-mode, M-mode, and Doppler echocardiographic images were recorded before and during the stimulation. When compared to baseline values, dobutamine at 5 $\mu \mathrm{g} / \mathrm{kg} / \mathrm{min}$ induced a significant increase of the left ventricular fractional shortening, of the systolic interventricular septum thickness, and of the left ventricular free wall thickness. Moreover, aortic and pulmonary peak flow velocities were significantly higher during than before dobutamine stimulation. These changes were similar in horses with and without cardiac murmurs. Two horses without murmur developed a cardiac murmur during dobutamine infusion, and in all horses with pre-existing murmur the intensity of the murmurs increased. In contrast, in horses with pre-existing valvular insufficiencies the Doppler echocardiographic examination revealed a decreased prevalence and magnitude of regurgitant flows during stimulation. Even if this study demonstrated, that dobutamine at a dose of $5 \mu \mathrm{g} / \mathrm{kg} / \mathrm{min}$ appeared to be well tolerated and to induce significant increases in systolic wall thickening and in left ventricular fractional shortening it is difficult to compare it to exercise, since heart rate, a major determinant of cardiac work, was not significantly increased during the test. In human stress echocardiography, the target heart rate is $85 \%$ of the individual age-predicted maximal heart rate in order to avoid suboptimal cardiac workload which could lower the test's sensitivity (Armstrong and Zoghbi 2005). The same is probably valid for the horse.

Since a high dobutamine infusion rate of $50 \mu \mathrm{g} / \mathrm{kg} / \mathrm{min}$ appears to be potentially cardiomyotoxic in horses and since a low dobutamine infusion rate of $5 \mu \mathrm{g} / \mathrm{kg} / \mathrm{min}$ appears to induce an insufficient increase in heart rate an alternative protocol has been tested in healthy Shetland ponies (Sandersen et al. 2005a). In this study, a group of seven ponies receiving a dobutamine infusion at a rate of $2 \mu \mathrm{g} / \mathrm{kg} / \mathrm{min}$ during five minutes, followed by increasing steps of $5 \mu \mathrm{g} / \mathrm{kg} / \mathrm{min}$ from 5 to $40 \mu \mathrm{g} / \mathrm{kg} / \mathrm{min}$ was compared to a group of six ponies receiving twice $25 \mu \mathrm{g} / \mathrm{kg}$ of atropine followed by a dobutamine infusion at incremental rates of $1 \mu \mathrm{g} / \mathrm{kg} / \mathrm{min}$ from 2 to $5 \mu \mathrm{g} / \mathrm{kg} / \mathrm{min}$, of 5 minutes duration each. In this latter study, cardiac output was measured as an indicator of global left ventricular function. As in the study of Frey et al. (2003), ponies that received the high dose of dobutamine showed excessive restlessness and ventricular arrhythmias during the test. In contrast, ponies receiving the low dose of dobutamine after atropine premedication showed less signs of restlessness, less inter-individual variability, and a higher increase in cardiac output, although they received a dobutamine infusion rate that was 8 times lower. This phenomenon might be explained by the atropine-induced inhibition of the baroreceptor reflex that is induced by high-dose dobutamine. The protocol used in this study appeared to induce a cardiac stimulation of a similar magnitude than maximal exercise, to be well tolerated, and to give the possibility to record high quality images during an adequate cardiac stress test in horses.

The protocol was then slightly modified and used with a lower dose of atropine as tested in a study by Sandersen et al. (2006), where seven horses were premedicated with $35 \mu \mathrm{g} / \mathrm{kg}$ of atropine followed by a continuous infusion of increasing dobutamine rates up to a maximal rate of $6 \mu \mathrm{g} / \mathrm{kg} / \mathrm{min}$. Left ventricular $\mathrm{M}$-mode parameters were recorded before and during each step of the pharmacological challenge. Systolic and diastolic interventricular septum thickness, systolic and diastolic left ventricular free wall thickness and left ventricular fractional shortening increased significantly, whilst systolic and diastolic left ventricular internal diameter significantly decreased during pharmacological stimulation.

The advantageous effect of atropine on low-dose dobutamine stress test has recently been used in another study by Gehlen et al. (2006), in which 10 healthy horses first received a dobutamine infusion of $7.5 \mu \mathrm{g} / \mathrm{kg} / \mathrm{min}$ and then a bolus injection of $5 \mu \mathrm{g} / \mathrm{kg}$ of atropine during the dobutamine infusion. Two out of ten horses needed a second dose of 2.5 $\mu \mathrm{g} / \mathrm{kg}$ of atropine in order to reach a target heart rate of more than 100 bpm. Left ventricular echocardiographic parameters were recorded before and during the pharmacological challenge and were compared to echocardiographic values obtained after treadmill exercise. Both stressors induced a significant decrease in left ventricular dimensions and in stroke volume, and a significant increase in left ventricular wall thicknesses. Those changes were more pronounced during the pharmacological stimulation than after exercise. The effects of various cardiac stress protocols on heart rate and echocardiographic parameters in horses are summarized in table 2.

Other pharmacological stressors have been tested in horses, but did not give satisfying results. Gehlen et al. (2005c) tested adrenaline as a pharmacological stressor. $M$ - and B-mode images were recorded in 10 healthy horses before and during infusion with $1 \mathrm{mg} / \mathrm{kg} / \mathrm{min}$ adrenaline during 6 minutes. Mmode derived systolic and diastolic left ventricular internal diameter significantly decreased and the diastolic interventricular septum thickness significantly increased during the stimulation with adrenaline when compared to baseline values. The volume of the left ventricle, based on B-mode measurements, was significantly smaller during stimulation with adrenaline. The tested horses showed multiple side effects: from the 10 tested horses, all showed sweating, 7 trembling, 3 headshaking, and 4 rapid movements of tail or limbs. The mean heart rate during the adrenaline infusion was $55 \mathrm{bpm}$. Even though adrenaline induced a significant increase in myocardial contractility, it did not appear to be an ideal pharmacological stressor for cardiac stress testing in horses, because adrenaline-induced changes are less important than those observed after exercise and because horses showed multiple side effects during adrenaline infusion at a rate of $1 \mu \mathrm{g} / \mathrm{kg} / \mathrm{min}$.

Noradrenaline has been tested on healthy Warmblood horses at an infusion rate of $1 \mu \mathrm{g} / \mathrm{kg} / \mathrm{min}$, but side effects were simi- 
Table 2 Left ventricular echocardiographic M-mode parameters reported in various studies on stress echocardiography in horses. Linke ventikuläre echokradiographische B-mode-Parameter unterschiedlicher Studien über Stressechokardiographie beim Pferd.

\begin{tabular}{|c|c|c|c|c|c|c|c|c|c|}
\hline Authors & $\begin{array}{c}\text { Cardiac } \\
\text { stimulation }\end{array}$ & $\begin{array}{c}\mathrm{HR} \\
(\mathrm{bpm})\end{array}$ & $\begin{array}{l}\text { LVIDd } \\
(\mathrm{cm})\end{array}$ & $\begin{array}{l}\text { LVIDs } \\
(\mathrm{cm})\end{array}$ & $\begin{array}{l}\text { IVSd } \\
(\mathrm{cm}) \\
\end{array}$ & $\begin{array}{l}\text { IVSs } \\
(\mathrm{cm})\end{array}$ & $\begin{array}{l}\text { LVFWd } \\
(\mathrm{cm})\end{array}$ & $\begin{array}{l}\text { LVFWs } \\
(\mathrm{cm})\end{array}$ & $\begin{array}{l}\text { FS } \\
(\%)\end{array}$ \\
\hline \multirow[t]{2}{*}{$\begin{array}{l}\text { Marr et al. } \\
\text { (1999) }\end{array}$} & baseline & $36 \pm 6$ & $\begin{array}{c}11.95 \pm \\
0.52\end{array}$ & $\begin{array}{c}7.31 \pm \\
0.57\end{array}$ & $\begin{array}{c}3.28 \pm \\
0.41\end{array}$ & $\begin{array}{c}4.92 \pm \\
0.30\end{array}$ & $\begin{array}{c}2.23 \pm \\
0.25\end{array}$ & $\begin{array}{c}3.87 \pm \\
0.87\end{array}$ & $\begin{array}{c}38.6 \pm \\
5.41\end{array}$ \\
\hline & post-EX & $97 \pm 6$ & $\begin{array}{c}11.80 \pm \\
1.22\end{array}$ & $\begin{array}{c}7.45 \pm \\
1.31\end{array}$ & $\begin{array}{c}3.43 \pm \\
0.16\end{array}$ & $\begin{array}{c}4.82 \pm \\
0.73\end{array}$ & $\begin{array}{c}2.06 \pm \\
0.37\end{array}$ & $\begin{array}{c}3.50 \pm \\
0.34\end{array}$ & $\begin{array}{c}36.7 \pm \\
7.32\end{array}$ \\
\hline \multirow[t]{2}{*}{$\begin{array}{l}\text { Sampson et } \\
\text { al. (1999) }\end{array}$} & baseline & $55 \pm 2$ & $\begin{array}{c}11.1 \pm \\
0.1\end{array}$ & $6.1 \pm 0.1$ & $3.2 \pm 0.1$ & $5.1 \pm 0.1$ & $2.1 \pm 0.1$ & $4.5 \pm 0.1$ & NR \\
\hline & post-EX & $112 \pm 3$ & $\begin{array}{c}10.9 \pm \\
0.2\end{array}$ & $6.2 \pm 0.2$ & $3.4 \pm 0.1$ & $5.2 \pm 0.1$ & $2.0 \pm 0.1$ & $4.2 \pm 0.1$ & NR \\
\hline \multirow[t]{2}{*}{$\begin{array}{l}\text { Frye et al. } \\
(2003)\end{array}$} & Post-DO & $161 \pm 7$ & $\begin{array}{c}9.73 \pm \\
0.27\end{array}$ & $\begin{array}{c}4.31 \pm \\
0.28\end{array}$ & $\begin{array}{c}2.79 \pm \\
0.13\end{array}$ & $\begin{array}{c}4.78 \pm \\
0.18\end{array}$ & $\begin{array}{c}2.15 \pm \\
0.13\end{array}$ & $\begin{array}{c}4.06 \pm \\
0.12\end{array}$ & NR \\
\hline & post-EX & $160 \pm 7$ & $\begin{array}{c}9.26 \pm \\
0.25\end{array}$ & $\begin{array}{c}4.99 \pm \\
0.31\end{array}$ & $\begin{array}{c}2.59 \pm \\
0.12\end{array}$ & $\begin{array}{c}4.03 \pm \\
0.13\end{array}$ & $\begin{array}{c}2.37 \pm \\
0.12\end{array}$ & $\begin{array}{c}3.91 \pm \\
0.18\end{array}$ & NR \\
\hline \multirow{2}{*}{$\begin{array}{l}\text { Gehlen et al. } \\
(2004)\end{array}$} & baseline & 36 & NR & $7.4 \pm 0.9$ & NR & $4.7 \pm 0.6$ & NR & NR & $38 \pm 5$ \\
\hline & DO $5 \mu \mathrm{g} / \mathrm{kg} / \mathrm{min}$ & $37 \pm 5$ & NR & $6.4 \pm 0.9$ & NR & $5.0 \pm 0.6$ & NR & NR & $47 \pm 6$ \\
\hline \multirow[t]{2}{*}{$\begin{array}{l}\text { Gehlen et al. } \\
(2005 a)\end{array}$} & baseline & $36 \pm 6$ & $\begin{array}{c}12.3 \pm \\
0.2\end{array}$ & $8.3 \pm 2$ & $2.3 \pm 0.1$ & $2.9 \pm 0.1$ & $2.1 \pm 0.3$ & $3.4 \pm 0.2$ & $33 \pm 3$ \\
\hline & post-EX & $114 \pm 6$ & $11.2 \pm 9$ & $7.9 \pm 8$ & $2.5 \pm 0.3$ & $3.1 \pm 0.4$ & $2.3 \pm 0.4$ & $3.6 \pm 0.4$ & $38 \pm 5$ \\
\hline \multirow[t]{3}{*}{$\begin{array}{l}\text { Sandersen et } \\
\text { al. (2006) }\end{array}$} & baseline & $40.7 \pm 7$ & $\begin{array}{c}10.79 \pm \\
0.68\end{array}$ & $\begin{array}{c}7.02 \pm \\
0.65\end{array}$ & $\begin{array}{c}2.88 \pm \\
0.19\end{array}$ & $\begin{array}{c}4.51 \pm \\
0.27\end{array}$ & $\begin{array}{c}2.43 \pm \\
0.28\end{array}$ & $\begin{array}{c}3.72 \pm \\
0.34\end{array}$ & $\begin{array}{c}34.98 \pm \\
3.82\end{array}$ \\
\hline & $\begin{array}{c}\text { ATR } 35 \mu \mathrm{g} / \mathrm{kg} \\
\text { DO } 2 \mu \mathrm{g} / \mathrm{kg} / \mathrm{min}\end{array}$ & $113 \pm 15$ & $\begin{array}{c}9.16 \pm \\
0.52\end{array}$ & $\begin{array}{c}5.31 \pm \\
0.53\end{array}$ & $\begin{array}{c}3.18 \pm \\
0.41\end{array}$ & $\begin{array}{c}4.96 \pm \\
0.45\end{array}$ & $\begin{array}{c}2.77 \pm \\
0.32\end{array}$ & $\begin{array}{c}4.24 \pm \\
0.59\end{array}$ & $\begin{array}{c}41.86 \pm \\
7.36\end{array}$ \\
\hline & $\begin{array}{l}\text { ATR } 35 \mu \mathrm{g} / \mathrm{kg} \\
\text { DO } 6 \mu \mathrm{g} / \mathrm{kg} / \mathrm{min}\end{array}$ & $157 \pm 13$ & $\begin{array}{c}9.42 \pm \\
0.56\end{array}$ & $\begin{array}{c}4.63 \pm \\
0.16\end{array}$ & $\begin{array}{c}3.78 \pm \\
0.16\end{array}$ & $\begin{array}{c}5.65 \pm \\
0.31\end{array}$ & $\begin{array}{c}3.11 \pm \\
0.34\end{array}$ & $\begin{array}{c}4.77 \pm \\
0.18\end{array}$ & $\begin{array}{c}50.56 \pm \\
3.42\end{array}$ \\
\hline \multirow[t]{3}{*}{$\begin{array}{l}\text { Gehlen et al. } \\
(2006)\end{array}$} & baseline & $37 \pm 5$ & $\begin{array}{c}12.0 \pm \\
0.84\end{array}$ & $\begin{array}{c}8.09 \pm \\
0.91\end{array}$ & $\begin{array}{c}2.38 \pm \\
0.29\end{array}$ & $\begin{array}{c}2.79 \pm \\
0.26\end{array}$ & $\begin{array}{c}2.15 \pm \\
0.26\end{array}$ & $\begin{array}{c}3.22 \pm \\
0.38\end{array}$ & $\begin{array}{c}32.5 \pm \\
1.14\end{array}$ \\
\hline & Post-EX & $136 \pm 18$ & $\begin{array}{c}11.03 \pm \\
0.96\end{array}$ & $\begin{array}{c}7.64 \pm \\
0.91\end{array}$ & $\begin{array}{c}2.59 \pm \\
0.38\end{array}$ & $\begin{array}{c}2.93 \pm \\
0.25\end{array}$ & $\begin{array}{c}2.27 \pm \\
0.48\end{array}$ & $\begin{array}{c}3.52 \pm \\
0.4\end{array}$ & $\begin{array}{c}30.2 \pm \\
1.22\end{array}$ \\
\hline & $\begin{array}{c}\text { DO } 7.5 \mu \mathrm{g} / \mathrm{kg} / \mathrm{min} \\
\text { ATR } 5 \mu \mathrm{g} / \mathrm{kg}\end{array}$ & $123 \pm 8$ & $\begin{array}{c}10.0 \pm \\
1.14\end{array}$ & $\begin{array}{c}7.39 \pm \\
1.4\end{array}$ & $\begin{array}{c}2.86 \pm \\
0.35\end{array}$ & $\begin{array}{c}2.98 \pm \\
0.24\end{array}$ & $\begin{array}{c}2.39 \pm \\
0.36\end{array}$ & $\begin{array}{c}3.71 \pm \\
0.58\end{array}$ & $\begin{array}{c}23.5 \pm \\
1.73\end{array}$ \\
\hline
\end{tabular}

lar to those described after adrenaline administration. Moreover, noradrenaline induced cardiac arrhythmias including severe multiple successive second degree atrio-ventricular blocs and sinus pauses of more than 3 seconds (Sandersen et al. 2005b).

\section{Conclusion}

In conclusion, stress echocardiography can be considered as a potential tool in the diagnosis and prognosis of cardiac disease in horses and can be performed either in the immediate post-exercise period or during a pharmacological stimulation. Pharmacological stress is best induced by a combination of atropine and low doses of dobutamine and has several advantages over post-exercise imaging, noteworthy, the prolonged time-interval for image acquisition and the better image quality. The studies performed until now demonstrate that changes in left ventricular $\mathrm{M}$-and B-mode parameters are similar or even more pronounced during pharmacological stimulation than those obtained after exercise. Future studies should demonstrate the usefulness of this technique in horses suffering from cardiac disease.

\section{References}

Armstrong W. F. and Zoghbi W. A. (2005): Stress echocardiography. J. Am. Coll. Cardiol. 45, 1739-1747

Autenrieth G., Angermann C., Goss F. and Bolte H. D. (1977): Stress echocardiography in patients with coronary heart disease.Verh. Dtsch. Ges Inn. Med. 83, 231-236

Banister E. W. and Purvis A. D. (1968): Exercise electrocardiography in the horse by radiotelemetry. J. Am. Vet. Med. Assoc. 152, 1004-1008

Bassan L. and OH W. (1968) Radiotelemetric studies of the heart rate in race horses at rest and in all paces (walk, trot, gallop)]. Arch. Exp. Veterinärmed. 22, 57-75

Blissit K. J. and Bonagura J. D. (1995a): Color flow Doppler echocardiography in normal horses. Equine Vet. J. Suppl. 19, 47-55

Blissit K. J. and Bonagura J. D. (1995b): Color flow Doppler echocardiography horses with cardiac murmurs. Equine Vet. J. Suppl. $19,82-85$

Carstensen S., Ali S. M., Stensgaard-Hansen F. V., Toft J., Haunso S., Kelbaek H. and Saunamaki K. (1995): Dobutamine-atropine stress echocardiography in asymptomatic healthy individuals. Circulation. 92, 3453-3463

Cerqueira M. D., Weissmann M. J., Dilzisian V., Jacobs A. K., Kaul S., Laskey W. K., Pennel D. J., Rumberger J. A., Ryan T. and Verani M. S. (2002): Standardized Myocardial segmentation and nomenclature for tomographic imaging of the heart. Circulation. 105, 539-542 
Cohen J. L., Greene T. O., Ottenweller J., Binenbaum S. Z., Wilchfort S. D. and Kim C. S. (1991): Dobutamine digital echocardiography for detecting coronary artery disease. Am. J. Cardiol. 67, 1311-1318

Dagenais G. R., Rouleau J. R., Christen A. and Fabia J. (1982): Survival of patients with a strongly positive exercise electrocardiogram. Circulation 65, 452-456

Durando M. M., Reef V. B. and Birks E. K. (2002): Right ventricular pressure dynamics during exercise: relationship to echocardiography. Equine Vet. J. Suppl. 34, 472-477

Frye M. A., Bright J. M., Dargatz D. A., Fettmann M. J., Frisbie D. D., Baker D. C. and Traub-Cargatz J. L. (2003): A comparison of dobutamine infusion to exercise as a cardiac stress test in healthy horses. J. Vet. Int. Med. 17, 58-64

Gehlen H., Becker J., Deegen E. and Stadler P. (2004): Veränderung echokardiographischer Funktionsparameter unter Dobutaminwirkung bei Warmblutpferden mit und ohne Herzgeräusch. Wien. Tieraerztl. Mschr. 91, 103-111

Gehlen H., Marnette S. and Stadler P. (2005a): Stressechokardiographie beim Warmblutpferd: aktive Stressinduktion durch Laufband- und Longenbelastung. Pferdeheilkunde 21, 303-310

Gehlen H., Marnette S. Rohn K. and Stadler P. (2005b): Echocardiographic Analysis of Segmental left ventricular wall motion at rest and after exercise in horses with and without heart disease. J. Equine Vet. Science. 25, 468-479

Gehlen H., Marnette S. and Stadler P. (2005c): The influence of adrenaline on echocardiographic parameters of left ventricular function in the horses. Equine Comp. Exercise. Physiol. 2, 89-96

Gehlen H., Marnette S., Rohn K. and Stadler P. (2006): Stress echocardiography in warmblood horses: Comparison, of Dobutamin/ Atropine with Treadmill exercise as cardiac stressors. J. Vet. Int Med. 20, 562-568

Geleijnse M. L, Elhendy A., Kasprzak J. D., Rambaldi R., van Domburg R. T., Cornel J. H., Klootwijk A. P., Fioretti P. M., Roelandt J. R. and Simoons M. L. (2000): Safety and prognostic value of early dobutamine-atropine stress echocardiography in patients with spontaneous chest pain and a non-diagnostic electrocardiogram. Eur Heart J. 5, 397-406

Glendenning S. A. (1972): Significance of clinical abnormalities of the heart in soundness. Equine Vet. J. 4, 21-30

Henry T. D., Atkins J. M., Cunningham M. S., Francis G. S., Groh W. J., Hong R. A., Kern K. B., Larson D. M., Ohman E. M., Ornato J. P., Peberdy M. A., Rosenberg M. J. and Weaver W. D. (2006) STsegment elevation myocardial infarction: recommendations on triage of patients to heart attack centers: is it time for a national policy for the treatment of ST-segment elevation myocardial infarction? J. Am. Coll. Cardiol. 47, 1339-1345

Kriz N. G., Hodgson D. R. and Rose R. J. (2000) Prevalence and clinical importance of heart murmurs in racehorses. J. Am. Vet. Med. Assoc. 9, 1441-1445

Leavitt J. I., Coats M. H. and Falk R. H. (1991): Effect of exercise on transmitral gradient and pulmonary artery pressure in patients with mitral stenosis or a prothetic mitral valve. J. Am. Coll. Cardiol. 17 1520-1526

Marr C. M., Bright J. M., Marlin D. J., Harris P. A. and Roberts C. A. (1999): Pre- and post exercise echocardiography in horses performing treadmill exercise in cool and hot/humid conditions. Equine Vet. J. Suppl. 30, 131-136

Martin B. B., Reef V. B., Parente E. J. and Sage A. D. (2002): Causes of poor performance in horses during racing, training or showing: 348 cases (1992-1996). J Am Vet Med Assoc. 216, 554-558

Marwick T. H. (2003): Stress echocardiography. Heart. 89, $113-118$

Mitten L. A. (1996): Cardiovascular causes of exercise intolerance. Vet. Clin. North Am.: Equine Practice. 12, 473-494

Patesson M. W. and Cribbs P. J. (1993): A survey of cardiac auscultatory findings in horses. Equine Vet. J. 25, 409-415

Patteson M. W. (1995): Cardiac arrhythmias. In: PAtteson M.W. (ed) Equine Cardiology. Oxford: Blackwell Science. pp. 231-345

Picano E. (2004): Stress echocardiography. Expert. Rev. Cardiovasc. Ther. 2, 77-88

Picano E., Lattanzi F., Orlandi A., Marini C. and L'Abbate (1991): Stress echocardiography and the human factor: the importance of being an expert. J. Am. Coll. Cardiol.17, 666-669
Pierard L. A., De Landsheere C. M., Berthe C., Rigo P. and Kulbertus HE. (1990): Identification of viable myocardium by echocardiography during dobutamine infusion in patients with myocardial infarction after thrombolytic therapy: comparison with positron emission tomography.J Am Coll Cardiol. 15, 1021-1031

Pipers F. S and Hamlin R. L. (1977): Echocardiography in the horse. J Am Vet Med Assoc. 170, 815-819.

Poldermans D., Fioretti P. M., Forster T., Thomson I. R., Boersma E., el-Said E. M., du Bois N. A., Roelandt J. R. and van Urk H. (1993): Dobutamine stress echocardiography for assessment of perioperative cardiac risk in patients undergoing major vascular surgery. Circulation. 87, 1506-1512.

Poldermans D., Arnese M., Fioretti P. M., Salustri A., Boersma E., Thomson I. R., Roelandt J. R. and van Urk H. (1995): Improved cardiac risk stratification in major vascular surgery with dobutamineatropine stress echocardiography. J Am Coll Cardiol. 26, 648-653

Previtali M., Poli A., Lanzarini L., Fetiveau R., Mussini A. and Ferrario M. (1993) Dobutamine stress echocardiography for assessment of myocardial viability and ischemia in acute myocardial infarction treated with thrombolysis. Am. J. Cardiol. 72, 124G-130G.

Reef V .B. (1992): Heart murmurs in horses. Determining the significance with echo- cardiography. In proceedings of the 10th Annual Americam College of Veterinary Internal Medicine Forum, 1992. pp. 442-444

Reef V. B., Maxson A. D. and Lewis M. (1994): Echocardiographic and ECG changes in horses following exercise. Am. Coll. Vet. Int. Med. Annual Forum 12, 256-258

Reef V.B. (1997): Electrocardiography and Echocardiography in the Exercising Horse. in Robinson N.E. (ed.) Current Therapy in equine medicine. 4th ed. Saunders, London, pp. 234-239

Reef V. B. (2001): Stress echocardiography and its role in performance assessment. Vet. Clin. North Am.: Equine Practice. 17, 179-189

Sampson S. N., Tucker R. L. and Bayly W. M. (1999): Relationship between VO2max, heart score, and echocardiographic measurements obtained at rest and immediately following maximal exercise in Thoroughbred horses. Equine Vet. J. Suppl. 30, 190-194

Sandersen C., Detilleux J., Delguste C., Pierard L., Ven Loon G. and Amory H. (2005a): Atropine reduces dobutamine-induced side effects in ponies undergoing a pharmacological stress protocol. Equine Vet. J. 37, 128-137.

Sandersen C., Peters F., Pequito M., Vittoz S., Serteyn D. and Amory H. (2005b) Norepinephrine induces multiple 2nd degree atrioventricular blocks in healthy conscious horses. Pflugers Arch. Europ. J. Physiol. 450, R10

Sandersen C., Detilleux J., De Moffarts B., Van Loon G. and Amory H. (2006) Effect of Atropine-Dobutamine Stress Test on left ventricular eechocardiographic parameters in untrained warmblood horses. J. Vet. Int. Med. 20, 575-580

Schiller N. B., Shah P. M., Crawford M., DeMaria A., Deveraux R. and Feigenbaum H. (1989): Recommendations for quantification of the left ventricle by two-dimensional echocardiography. Eur. Heart J. $10,910-916$

Smart S. C., Sawada S., Ryan T., Segar D., Atherton L., Berkovitz K., Bourdillon P. D. and Feigenbaum H. (1993): Low-dose dobutamine echocardiography detects reversible dysfunction after thrombolytic therapy of acute myocardial infarction. Circulation. 88, 405-415

Verdegaal L. J., Voorhut G., Van Loon G. and Sloet van OldruitenborghOsterbaan M. (2002): Herzgeräusch als Zufallsbefunde bei tierärztlichen Kauf- oder Verfassungsprüfungen -Befundung und Verlauf bei 77 klinisch gesunden Pferden. Pferdeheilkunde 18, 263-272

Watada $H_{\text {., }}$ Ito H., Oh H., Masuyama T., Aburaya M., Hori M., Iwakura M., Higashino Y., Fujii K. and Minamino T. (1994): Dobutamine stress echocardiography predicts reversible dysfunction and quantitates the extent of irreversibly damaged myocardium after reperfusion of anterior myocardial infarction. J. Am. Coll. Cardiol. 24, 624-630

Wu W. C., Aziz G. F. and Sadaniantz A. (2004): The Use of Stress Echocardiography in the Assessment of Mitral Valve Disease. Echocardiography. 21, 451-458

Charlotte Sandersen

University of Liege, Faculty of Veterinary Medicine

Dept. of Clinical Sciences

Blvd. de Colonster 20, B4 1, 4000 Liege, Belgium

charlotte.sandersen@ulg.ac.be 